\title{
The Present Situation and Adjustment of the Service Function of Chongqing Functional Financial Center (FFC)
}

\author{
Ran Lian \\ Rongzhi College of CTBU \\ ChongQing, China \\ Email:1076474311@qq.com
}

\author{
Liyao Jin \\ ChongQing Technology and Bussiness University \\ ChongQing, China \\ Email:1542536084@qq.com
}

\begin{abstract}
With similarities of the construction of the financial center, many cities begin to plan different roads of the financial center. The 19th CPC National Congress of the Party and President $\mathrm{Xi}$ further emphasized the strategic significance of Chongqing as an open highland in China's western region in early 2016 and positioned it as a functional financial center. This paper quantifies the five functions of Chongqing in the past $\mathbf{2 0}$ years, namely financial settlement, financial transaction, capital financing, insurance protection and financial inclusion. Finally it is found that the function of financial transactions has improved since 2016, but the development of other functions is uneven and limited.
\end{abstract}

\section{Keywords-FFC; Functional orientation; Factor analysis}

\section{INTRODUCTION}

As the main carrier of financial industry, financial center has become an important symbol of economic development of a country or a region. At present, more than 30 cities have proposed the construction of regional financial center, which is homogenous and competitive. Based on the disordered competition of financial resources among the regional financial centers in China, many scholars have begun to realize the importance of the function of the financial center. Pengfei Ni (2005) used the fuzzy curve analysis method to select indexes from the aspects of talent, capital, science and technology, location, facilities, environment, etc, which proved the important role of financial center's positioning [1]. Hanjun Han (2006) also focused on the construction and the breakthrough of financial service function in Shanghai [2]. In 2007, Dr.Yang Xianyue, researcher of Shanghai Academy of Social Sciences, used "competition in a vacuum" to describe the current competition among major cities in China, and pointed out that in the context of such competition, the focus should be on the functioning of financial centers.

What are the functions of financial centers? The traditional view is that financial center functions mainly include financing, investment, information service, resource allocation and risk aversion, etc. This view is mainly based on the carrier of financial center. However, the function of the financial center is not exactly equal to the function of finance. In recent years, many scholars have realized that the function of financial center has evolved new features on the basis of core functions. Yu Xiurong (2011) argued that the core function of international financial center is the aggregation and radiation of international financial resources. With the continuous development of the financial center, the core function has been upgraded and changed, and at the same time, specific functions such as pricing of financial assets, distribution of financial risks and redistribution of international wealth have emerged [3]. Similarly, starting with the classical theory, Sun Guomao (2013) analyzed the nature, characteristics and basic functions of the financial center. He believed that the essential characteristics of different levels of financial center are the same, but the basic functions are different. It can be divided into three core functions, such as aggregation function, radiation function, transaction function, and general functions such as information creation, credit creation, financial innovation and so on. Among them, the core function is the development basis of the general function, and the general function is the main function difference of different financial centers [4].

Based on the changes of the functions of financial centers, scholars began to study the development of specific financial center from the perspective of function. Jiesheng Li (2014) thinks that the Shanghai financial center should perfect payment and settlement, capital pricing, investment and financing function [5]. Ming-xi zhang (2016)focuses on the function, characteristics and organizational structure of the $\mathrm{S}$ $\& \mathrm{~T}$ (science and technology) financial center from a theoretical point of view, and holds that the function of the STFC is different from that of the general financial center, and its function is mainly manifested in innovation, aggregation, radiation and development [6]. Based on the theory of platform economy, Lianying Hong (2017) compared Hong Kong and Singapore, and analyzed the positioning of Shanghai's investment facilitation and international financial center, the opening of service industry and the orientation of service trade center, the orientation of science and technology innovation and service industry center. It is found that the functional orientation of Shanghai is ahead of the actual economic conditions of Shanghai, so some adjustments should be made on the functional orientation of Shanghai [7]. Based on the functional demand of building the financial center, Yifu Tang (2017) believes that the Chongqing financial center 
should build agglomeration and radiation function as the core function, and four key functions-settlement, economic structure adjustment, value discovery and risk management, combined with financial innovation, information distribution, asset restructuring, inclusive finance and so on [8]. It can be seen that the function orientation of the specific financial center is based on the function of aggregation and radiation and evolves a new focus of function development according to the demand of local economic development.

In the new era, the central government has put forward new requirements for the development of Chongqing financial center. Both the 19th National Congress of the Party and President Xi Jinping's Chongqing speech at the beginning of 2016 stressed that Chongqing's financial development potential is enormous, and that Chongqing should properly position itself as a function in the large-scale development of the western region. New requirements are put forward for it to play a greater role in the development of the Yangtze River economic belt. Therefore, in December 2016, The 13th FiveYear Plan for the Construction of an Important Domestic Functional Financial Center in Chongqing further positioned Chongqing as a functional financial center with RMB crossborder settlement as a breakthrough. This paper innovatively constructs the index system from the angle of the function of the financial center, inspects the function service level of the current financial center of Chongqing, and seeks the point of the construction of the functional financial center, in order to accelerate the construction of functional Financial Center.

\section{The ConNotation AND PRESENT SituAtion OF FUNCTIONAL FINANCIAL CENTER}

\section{A. The connotation of functional financial center}

As early as the construction of Chongqing regional financial center, the government and many scholars pointed out the importance of the development of Chongqing functional financial center, and emphasized that settlement finance is the best breakthrough. In 2010, Chongqing became one of the pilot cities of RMB settlement of cross-border trade, and realized the great-leap-forward development of RMB cross-border settlement. At the end of December 2016, Chongqing's 13th Five-Year Plan formally defined the positioning of Chongqing's functional financial center. That is, under the premise of the continuous optimization of the financial ecological environment, focusing on the key areas of financial settlement, financial transactions, capital financing, insurance protection, financial inclusion, and basically forms the financial functions which are characteristic, different, have the important influence and competitiveness in the domestic. Among them, financial settlement function is the most important feature of Chongqing functional financial center.

\section{B. The present situation of functional financial center}

\section{1) Financial settlement}

The development trend of financial settlement function is strong. Since Chongqing became a RMB cross-border pilot in 2010, the Chongqing Ministry of Foreign Affairs has strongly supported various organizations in setting up settlement centers in Chongqing. For example, Puhui set its settlement center in Chongqing in 2010. Also, in 2014, multinational companies such as Guangda, Waichuang and Lifan Group set up their settlement funds in Chongqing. Besides, in 2016, relevant departments have promoted the facilitation of crossborder settlement through the establishment of land transport, multimodal transport, land international trade financing rules, and the establishment of supporting systems such as issuing, picking up goods, registering and querying, increasing credit, and so on, which made a remarkable effect. Data show that by the end of August 2017, HP settlement center had completed a total settlement volume of $\$ 509.9$ billion, accounting for $1 / 6$ of its global capital flow; 11 multinational companies operating in foreign exchange funds have realized \$46billion in cash receipts and payments; Lifan Group entered the interbank foreign exchange market with a cumulative amount of \$3.82billion; Cross-border e-commerce continues to grow rapidly, with a cumulative settlement of us $\$ 3.57$ billion.

\section{2) Financial transaction}

Thanks to the advantages of "Belt and Road" and the Yangtze Economic Belt, Chongqing has become a new trade hub, and the scale of local financial element markets, which reflects the situation of financial transaction, has been expanding. For example, the coffee trading center in Chongqing reached $¥ 5,659,000,000$ in 2017 , an increase of $137.8 \%$; the size of the Chongqing financial factor market increased from $¥ 903,540,000,000$ in 2014 to $¥ 1,585$, $750,000,000$ in 2016; the trading volume in the commodity market was also increased from 228,67 million yuan in 2010 to 358,653 million yuan in 2016 ,increased by 14 times; the amount of financing in the stock market also increased from 3,161 million yuan in 1997 to 72,206 million yuan in 2016, an increase of 21 times.

\section{3) Capital financing}

The ability of financing has been optimized continuously. This financing function is realized mainly through domestic and foreign markets. In terms of the domestic market, according to Zhang Jinqing and other scholars' research, more than $70 \%$ of the domestic financing funds come from the banking system. Figure.1shows that since 1997, the scale of local and foreign currency deposits and loans in the banking system has continued to expand; 


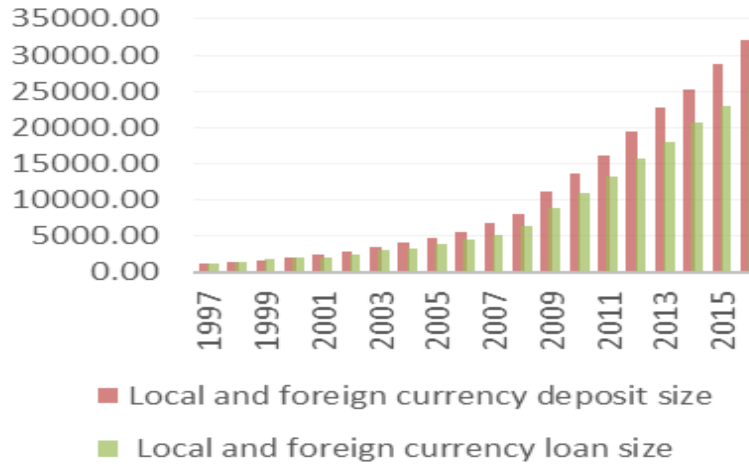

Fig. 1. Local and Foreign Currency Deposits and Loans in Chongqing

In terms of the overseas financing market, when the SinoSingapore financial cooperation project was established in Chongqing, it helped build a cross-border financing channel in Chongqing and the western region. The channel covers crossborder bond issuance, international commercial loans, financial leasing and other types of financing mode, benefiting nearly 20 districts and counties, introducing low-cost overseas funds for the development of Chongqing. The project has accumulated 55 cross-border financing, the total amount is more than $\$ 4$ billion, and the average combined financing cost is $4.86 \%$.

\section{4) Insurance protection}

The insurance industry has improved the support capacity of the real economy and the people's livelihood. On the one hand, the insurance industry has increased the protection of the real economy, especially export-oriented economy. In 2016, the Chongqing insurance industry supported 50 small and micro enterprises to obtain a bank loan of 43.2 million Yuan, and assisted 26 small and micro export enterprises to obtain a bank financing of about 410 million yuan, providing a short-term export credit insurance of $\$ 3.61$ billion dollars for 621 enterprises in the city, and providing an insurance guarantee for the overseas projects. On the other hand, the insurance industry has strengthened the support for the people's livelihood. In 2016, medical liability insurance has achieved full coverage of public hospitals above level II in the whole city, providing risk protection of 1,517 million yuan for 1969 hospitals. In the first half of 2017, the total assets of the insurance industry reached 145.896 billion yuan, up $15.610 \%$ from the beginning of the year. And the insurance premiums of the general life insurance and the dividend life insurance account for more than $60 \%$ of the insurance premiums in the whole city. As the proportion of guarantee-based products increasing rapidly, the role of insurance protection has been effectively played.

\section{5) Financial inclusion}

The level of financial inclusion has increased steadily. Small and micro-enterprises are the new force of development, the main channel of employment and the important source of innovation. Chongqing banking has actively promoted the establishment of a cooperative mechanism among government, banks and financing guarantee institutions, which has increased the loan application rate and loan satisfaction of small and micro enterprises. According to statistics, small and micro enterprises had a loan balance of 566.58 billion yuan at the end of 2016, accounting for $22 \%$ of all loan balances; the number of small and micro business loans was 22.32 million, an increase of 4,469 over the same period last year; the rate of loan acquisition for small and micro businesses was $94.44 \%$, 1.12 percentage points higher than in the same period last year.

\section{EMPIRICAL ANALYSIS ON THE FUNCTIONAL SERVICES OF CHONGQING FFC}

\section{A. Determination of Index system}

According to the functional positioning of Chongqing functional financial center, Chongqing will realize its five functions (financial settlement, financial transaction, capital financing, insurance protection and financial inclusion) through the construction of functional financial center. So this article selects indexes from these five angles (see table I).

\section{1) Financial settlement}

Capital flows between offshore and onshore markets through both trade and direct investment. Because the scale of direct investment is small, the development time is short, so like the previous research, this paper only used the crossborder RMB settlement amount to measure the settlement scale.

\section{2) Financial transaction}

According to the previous document and literature research, it is found that the function of financial transaction is mainly based on the factor market, which includes the asset market among financial institutions, oil and gas trading center, gold trading centers, rural land exchanges, shipping exchanges and other resource-based and physical trading centers, as well as trading centers for assets such as technology, film and television copyright, electricity, tourism, and so on. Taking the availability of data into consideration, this paper selects the direct financing amount to reflect the financial resources trading situation and the total transaction volume of the commodity market above 100 million yuan to reflect the transaction situation of the real economy. 


\section{3) Capital financing}

Capital financing refers to the provision of various financial instruments to both suppliers and demanders of funds to meet their transaction needs. It includes the circulation of money, the absorption and withdrawal of deposits, the issuance and recovery of loans, transactions in gold, silver, foreign exchange and securities, etc. In view of the development of the financial system in the western region is still dominated by the banking sector, this article selects the local foreign currency deposit scale and the local foreign currency loan scale to measure the capital financing situation.

\section{4) Insurance protection}

The insurance industry can provide a guarantee for the stable development of the economy through the innovation of its products and services. In the past, scholars selected premium income, compensation expenses and other largescale indicators, also, indicators reflecting its quality and the efficiency like the insurance density and the insurance depth will be chose. In this paper, the insurance density and insurance depth are selected.

\section{5) Financial inclusion}

According to the "Barrel Theory", whether the financial needs of the marginal groups, such as farmers and micro enterprises, can be satisfied directly affects the function of financial center. Therefore, according to the availability of data, this paper selects the loan ratio of small and mediumsized enterprises to measure the financial inclusion function of the financial center.

\section{TABLE I. INSTRUMENTAL FACTORS}

\begin{tabular}{ll}
\hline $\begin{array}{l}\text { financial settlement } \\
\text { the cross-border RMB settlement amount }\end{array}$ & $\begin{array}{l}\text { the direct financing amount ; the total transaction volume of the commodity market above } \\
100 \text { million yuan }\end{array}$ \\
financial transaction & the local foreign currency deposit scale; the local foreign currency loan scale \\
insurance protection & the insurance density ; the insurance depth \\
financial inclusion & the loan ratio of small and medium-sized enterprises
\end{tabular}

\section{B. Analyses and Results}

Given a certain correlation between the indexes, this paper needs to choose an analysis method that can not only overcome the correlation between the indicators, but also minimize the impact of subjective factors to compress the index dimension. Therefore, factor analysis is a suitable choice.
First, we reviewed the suitability of the indicators for factor analysis using the Kaiser-Meyer-Olkin (KMO) test. The test results (as shown in table 3.2) evidence that it is suitable for factor analysis since the value of KMO measured 0.75 , the concomitant probability of Bartlett's spherical test is 0.000 .

TABLE II. KMO AND BARTLETT'S TEST

\begin{tabular}{ccc}
\hline Kaiser-Meyer-Olkin Measure of Sampling Adequacy. & .750 \\
\hline \multirow{3}{*}{ Bartlett's Test of Sphericity } & Approx.Chi-Square & 346.103 \\
& $\mathrm{df}$ & 28 \\
& $\mathrm{Sig}$. & .000 \\
\hline
\end{tabular}

As the second step, we determined the number of factors and estimations of the factor loading coefficients to create new dimensions as latent variables. The contribution rates of the four factors were $6.508 \%, 24.957 \%, 20.302 \%$ and $17.59 \%$ respectively, and the accumulative contribution rate was $99.358 \%$.

In the final step, we name each factor and calculate the factor synthesis score. It is found that the fourth factor is related to the amount of direct financing, so it can be called the financial transaction factor, the third factor is closely related to the insurance depth, so it is called the insurance protection factor. The second factor is related to the loan ratio of small and medium-sized enterprises and the total transaction volume of more than 100 million yuan in commodity market, so it is called the financial inclusion factor. The first factor is related to the cross-border RMB settlement amount, insurance density, premium income, local and foreign currency deposit and loan scale and other indicators, so it is called financial settlement and financing function factors.

Then, we found that the comprehensive score of financial center is continuously rising, and the comprehensive service function of financial center is continuously optimized. As shown in figure2, It has been found that the functional factors have been developed rapidly for a period of time, but the five functions have been unbalanced. Recently, except the function of financial transaction, other functions have been restricted. 


\subsection{0 \\ 4.0000 \\ 2.0000 \\ 0.0000 \\ $-2.0000$ \\ $\multimap$ financial settlement and financing function factor $F 1$ \\ $\rightarrow$ - financial inclusion factor F2 \\ $\longrightarrow$ - insurance protection factor F3 \\ $\longrightarrow$ financial transaction factor $\mathrm{F} 4$ \\ $\rightarrow$ - the factor synthesis score}

a. Source: the Statistical Yearbook of Chongqing over the years, Chongqing Financial Statistics Bulletin, the people's Bank of China and the wind database, etc.

Fig. 2. Total Score of Chongqing Financial Center's Service Function

First of all, from the point of view of factor F1, which represents the functions of financial settlement and financing, it declined slightly in 2009, but rised from -1.32645 in 2009 to 3.38446 in 2015. This may be due to the fact that Chongqing became a cross-border pilot settlement of RMB in 2010, which led to the large-scale pooling of funds in Chongqing. The function has developed to a certain extent, but it began to decline again in 2016, which shown the limited development of the core function. Secondly, the factor F2, the degree of support and concern of microenterprises, that is, whether financial resources have effectively solved the problem of financial supply in the weak links of economic development, has declined from -0.28958 in 1997 to -1.36455 in 2009.From figure 3.1, after a brief rise of three years, it kept falling from 2.12321 in 2011 to -0.47205 in 2016 . It can be seen that there was a trend of deterioration that is the development of Chongqing's financial center in recent years has not really solved the problem of small and micro enterprises. Thirdly, the factor F3, which represents the function of insurance protection, has the greatest load on the depth of insurance. It is found that the factor has been increasing slowly from 1997 to 2009. In 2009, with the support of financial resources to the financial inclusion function, the function factor of insurance protection began to decline, and in recent years, there are only small fluctuations. The function has little driving force. Finally, from the point of view of factor F4, which represents the function of financial transactions, this factor has only developed slowly after 1997, and has improved markedly since 2012. But the rapid decline from 0.43353 in 2014 to 1.60781 in 2015 and the rise to 3.80794 in 2016 show that the construction of a financial trading platform in the city of Chongqing in recent years has begun to show success.

\section{SUGGESTIONS}

\section{A. Perfecting the Market system of Financial elements to strengthen the financial transaction function}

On the one hand, we should innovate the trading patterns and product categories of money market, insurance market and securities market. According to China's "Internet + " plan put forward by our country at present, the combination of Internet and transaction platform integrate the trans regional penetration and radiance of the Internet with the core functions of the factor market. So as to further enhance the transaction function of traditional factor market; On the other hand, we should build a multi-level factor markets and enrich the trading platform. For example, we will promote the establishment of technology elements, film and television copyright, and other asset trading platform. So as to expand and upgrade the transaction function of Chongqing functional financial center.

\section{B. Improving payment and settlement system to develop characteristic Financial settlement function}

With the development of financial center, more convenient, safe, low-cost payment and settlement system can help financial center to meet the diverse needs of residents and non-residents. At the same time, it also promotes the construction of supporting service facilities in the financial center, which is conducive to the safe and efficient operation of the financial market. Firstly, we should make full use of the basic functions of banking financial institutions' internal system, promote the integration of financial IC CARDS and public service applications, and expand the scope of bank card acceptance. Also, promoting the unification of Bill Market and Electronic process to strengthen the payment and settlement ability of Bill. Secondly, optimizing the multi-level payment clearing network. Strengthening the management of payment system and inter-bank clearing system to improve the safety and efficiency of payment and settlement infrastructure. Thirdly, we should encourage the combination of technology and payment, improve mobile payment and network payment operation environment, realizing cross-regional and crossinternational integration of resources and information sharing.

\section{Achieving balanced development of capital financing, insurance protection and financial inclusion}

As an open highland in the western region, Chongqing needs to exert its unique geographical advantages. Firstly, we should seize the opportunities of financial cooperation in the construction of China (Chongqing) pilot free trade zone and China-Singapore (Chongqing) strategic connectivity demonstration project, speed up the construction of the "Chongqing, New Europe" international logistics channel, create opportunities for cooperation with major overseas financial centers such as New York, London, Frankfurt, Singapore, Hong Kong, and expand international financing space for financing. Secondly, insurance products and services should be enriched, and insurance exhibition models could be innovated. Thirdly, we should strengthen the effective supply of financial resources to the weak link of economic development through perfecting the poverty alleviation service 
system and deepening the reform of rural property right mortgage financing. The scope of the collateral could be widened by carrying out rural land contract management right, farm house, forest right and other rural property rights mortgage financing.

\section{CONCLUSION}

In general, the function of Chongqing functional financial center is developing in the direction of diversification, but the development of each function is still very uneven. In the process of future development, we should focus on the development of core function-financial transaction, characteristic function-financial settlement, and at the same time, the development of financing, insurance protection and financial inclusion function needs to be taken into account.

\section{REFERENCES}

[1] Ni Pengfei, Sun Chengping. City of China: a study on the location of Financial Center [J]. Finance and Trade economy 2005 / 02: 17-22+96.

[2] Han Hanjun, Huang Enlong. The International experience of Urban Transformation and the Construction of Financial Service function in Shanghai [J]. Shanghai Economic Research 2005: 54-63.

[3] $\mathrm{Yu}$ Xiurong. Historical Evolution of the function of International Financial Center [J]. Journal of Henan normal University (philosophy and Social Sciences Edition), 2011, 38(02): 91-95.

[4] Sun Guomao, Fan Yuejin. The Nature, function and path Choice of Financial Center [J]. Management World, 2013(11): 1-13.

[5] Li Jiesheng. Study on the function of Shanghai Financial Center 19271937[D]. The Central University of Finance and Economics.

[6] Zhang Mingxi, Zhao Xiumei. The connotation, function and practice of S \& T Financial Center [J]. Scientific Management Research: 2016: 04: 101-105.

[7] Hong Lianying, Huang Ruxuan. Reflection on the functional orientation of Shanghai Free Trade Zone and its Adjustment-an Analysis based on the theoretical Framework of platform economy [J]. International Business Studies: 51: 54-64.

[8] Tang Yifu, Yao collar. The Framework Design and path selection of Building functional Financial Center in Chongqing [J]. Financial theory: 2017: 24-31. (In Chinese) 